\title{
Approaching trauma analgesia using prolonged and novel continuous peripheral nerve blocks - A case report -
}

\section{Eric Ly', Sai Velamuri ${ }^{2}$, William Hickerson ${ }^{2}$, David M. Hill ${ }^{3}$, Jay Desai ${ }^{2}$, Ban Tsui ${ }^{4}$, Michael Herr ${ }^{5}$, and Jerry Jones ${ }^{6}$}

${ }^{1}$ College of Medicine, Departments of ${ }^{2}$ Plastic Surgery, ${ }^{3}$ Clinical Pharmacy and Translational Science, The University of Tennessee Health Science Center, Memphis, TN, ${ }^{4}$ Department of Anesthesiology, The Stanford University Medical Center, Stanford, CA, Department of ${ }^{5}$ Anatomy and Neurobiology, ${ }^{6}$ Anesthesiology, The University of Tennessee Health Science Center, Memphis, TN, USA

Background: A supraclavicular brachial plexus nerve block provides analgesia for the shoulder, arm, and hand; however, the maximum safe duration for a continuous infusion remains controversial. A novel continuous peripheral nerve block (CPNB) technique combining the Lateral, Intermediate, and Medial femoral cutaneous nerves (termed the 'LIM' block) to provide analgesia to the lateral, anterior, and medial cutaneous areas of the thigh while preserving quadriceps strength will also be described in detail here.

Case: We present a complex case in which simultaneous utilization of an unilateral supraclavicular CPNB (5 weeks) and bilateral LIM CPNB (5 days) are successfully performed to provide analgesia for a traumatic degloving injury resulting in multiple surgeries.

Conclusions: The analgesic plan in this case study eliminated previous episodes of opioid-induced delirium, facilitated participation in recovery, and removed concerns for respiratory depression and chronic opioid use in a patient at particular risk for both issues.

Keywords: Acute pain service; Amputation; Analgesia; Anesthesia; Local anesthesia; Nerve block.
Traumatic injuries often cause significant acute pain, intensified by required surgeries and painful dressing changes. The amalgamation of complicated injuries and pain intensity requires complex analgesia to achieve adequate pain control. Prolonged healing time, combined with opioid-centric analgesia regimens expose patients to harmful, potentially avoidable, opioid-related adverse drug events (ORADEs) [1].

Continuous peripheral nerve blocks (CPNB) carry proven advantages in the setting of acute traumatic and post-surgical pain, including improved provision of analgesia and reduced ORADE's [2]. Post-intervention immobility is a disad- vantageous limitation of some CPNB techniques such as the fascia iliaca block due to the decrease in quadricep muscle strength and resulting increased risk in patient falls [3]. Further, the maximum safe duration for a continuous infusion remains controversial [4]. Herein, the authors present a case of simultaneous, continuous, and prolonged analgesia by employing a supraclavicular CPNB combined with a novel CPNB technique which provides continuous cutaneous analgesia to the thigh, while preserving motor strength and facilitating productive physical and occupational therapy sessions.

This is an Open Access article distributed under the terms of the Creative Commons Attribution Non-Commercial License (http://creativecommons.org/licenses/by-nc/4.0) which permits unrestricted non-commercial use, distribution, and reproduction in any medium, provided the original work is properly cited.

Copyright (C) the Korean Society of Anesthesiologists, 2022 


\section{CASE REPORT}

The patient provided written informed consent for publication of this case report and the associated images.

A 76-year-old male patient sustained injuries that included a comminuted left humerus midshaft fracture and a thermal contact abrasion with full thickness burns and degloving of the left shoulder, upper arm, and extensor surface of the lower arm and hand. His past medical history was significant for obesity, obstructive sleep apnea, type 2 diabetes mellitus, hypertension, and gastroesophageal reflux disease.

The patient immediately underwent an open reduction and internal fixation of the left humerus, followed by burn wound excision and application of allograft to the left upper extremity. Pain intolerance with dressing changes and opi- oid- associated delirium prompted an Acute Pain Service (APS) consultation. Accordingly, APS performed an ultrasound-guided, left supraclavicular CPNB (B Braun Contiplex Needle, B-Braun Medical Inc., USA) using $20 \mathrm{ml}$ of $0.5 \%$ bupivacaine followed by a $10 \mathrm{ml} / \mathrm{h}$ continuous infusion of $0.125 \%$ bupivacaine through an electronic infusion pump (CADD Solis infusion system, Smiths Medical, USA). Analgesia dramatically improved, and symptoms of delirium abated in parallel to reduced opioid consumption (Table 1). Prior to each of the remaining 7 surgeries performed under general anesthesia, APS bolused the supraclavicular CPNB with $20 \mathrm{ml}$ of $0.5 \%$ bupivacaine.

Thereafter, the patient underwent a below elbow amputation on hospital day (HD) 15. The supraclavicular CPNB was utilized as the primary anesthetic along with intravenous

Table 1. Opioids, Antibiotics, and Local Anesthetic Received During 5 Weeks of Procedures

\begin{tabular}{|c|c|c|c|c|c|}
\hline Opioids/Other & Week 1 & Week 2 & Week 3 & Week 4 & Week 5 \\
\hline Fentanyl & $\begin{array}{r}50 \mu \mathrm{g} \times 4^{*}, 100 \mu \mathrm{g} \times 5^{*}, \\
25 \mu \mathrm{g} \times 1^{*}, 100 \mu \mathrm{g} \times 1\end{array}$ & $50 \mu \mathrm{g} \times 2^{*}$ & $50 \mu \mathrm{g} \times 4^{*}$ & $100 \mu \mathrm{g} \times 3^{*}, 50 \mu \mathrm{g} \times 2^{*}$ & $100 \mu \mathrm{g} \times 1^{*}, 25 \mu \mathrm{g} \times 2^{*}$ \\
\hline Hydromorphone & $1 \mathrm{mg} \times 1^{*}, 0.5 \mu \mathrm{g} \times 3$ & 0 & 0 & $0.25 \mathrm{mg}$ & 0 \\
\hline Morphine, IV & $2 \mathrm{mg} \times 5,4 \mathrm{mg} \times 2$ & $2 \mathrm{mg} \times 4$ & 0 & 0 & 0 \\
\hline Oxycodone, oral & $10 \mathrm{mg} \times 4,5 \mathrm{mg} \times 1$ & $5 \mathrm{mg}$ & 0 & 0 & 0 \\
\hline Haloperidol & $1 \mathrm{mg} \times 3$ & 0 & 0 & 0 & 0 \\
\hline \multicolumn{6}{|l|}{ Bupivacaine use } \\
\hline \multirow{6}{*}{$\begin{array}{l}\text { Individual bupiva- } \\
\text { caine bolus quanti- } \\
\text { ty by surgery/ } \\
\text { events }\end{array}$} & (HD 2) $100 \mathrm{mg}$ & (HD 8) 100 mg & (HD 15) $100 \mathrm{mg}$ & (HD 23) 100 mg & (HD 30) $100 \mathrm{mg}$ \\
\hline & $0.77 \mathrm{mg} / \mathrm{kg}$ bolus $^{\dagger}$ & $0.77 \mathrm{mg} / \mathrm{kg}^{\dagger}$ & $0.77 \mathrm{mg} / \mathrm{kg}$ & $0.77 \mathrm{mg} / \mathrm{kg}^{\dagger}$ & $0.77 \mathrm{mg} / \mathrm{kg}^{\dagger}$ \\
\hline & (HD 4) 100 mg & & (HD 17) 25 mg & (HD 24) 25 mg & (HD 30) 150 mg \\
\hline & $0.77 \mathrm{mg} / \mathrm{kg}^{\dagger}$ & & $0.19 \mathrm{mg} / \mathrm{kg}^{\dagger}$ & $0.19 \mathrm{mg} / \mathrm{kg}^{\dagger}$ & $1.15 \mathrm{mg} / \mathrm{kg}^{\dagger}$ \\
\hline & & & & (HD 28) 100 mg & (HD 35) All CPNBs \\
\hline & & & & $0.77 \mathrm{mg} / \mathrm{kg}^{\dagger}$ & removed \\
\hline \multirow{3}{*}{$\begin{array}{l}\text { 24-hour total dose } \\
\text { from } 0.125 \% \text { bupiv- } \\
\text { acaine continuous } \\
\text { infusion per week }\end{array}$} & $10 \mathrm{ml} / \mathrm{hr}$ & $10 \mathrm{ml} / \mathrm{hr}$ & $10 \mathrm{ml} / \mathrm{hr}$ & $10 \mathrm{ml} / \mathrm{hr}$ & $18 \mathrm{ml} / \mathrm{hr}$ \\
\hline & $300 \mathrm{mg}$ & $300 \mathrm{mg}$ & $300 \mathrm{mg}$ & $300 \mathrm{mg}$ & $540 \mathrm{mg}$ \\
\hline & $2.3 \mathrm{mg} / \mathrm{kg}^{\dagger}$ & $2.3 \mathrm{mg} / \mathrm{kg}^{\dagger}$ & $2.3 \mathrm{mg} / \mathrm{kg}^{\dagger}$ & $2.3 \mathrm{mg} / \mathrm{kg}^{*}, \dagger$ & $4.15 \mathrm{mg} / \mathrm{kg}^{\dagger}$ \\
\hline \multicolumn{6}{|l|}{ Antibiotics } \\
\hline Cefepime & $2 \mathrm{~g} \times 14(\mathrm{q} 12 \mathrm{hr})$ & $2 \mathrm{~g} \times 14(\mathrm{q} 12 \mathrm{hr})$ & $2 \mathrm{~g} \times 14(\mathrm{q} 12 \mathrm{hr})$ & $2 \mathrm{~g} \times 14(\mathrm{q} 12 \mathrm{hr})$ & $2 \mathrm{~g} \times 14(\mathrm{q} 12 \mathrm{hr})$ \\
\hline Gentamicin & $160 \mathrm{mg} \times 1$ & 0 & 0 & 0 & 0 \\
\hline $\begin{array}{l}\text { Piperacillin and } \\
\text { tazobactam }\end{array}$ & $3.375 g \times 5$ & 0 & 0 & 0 & 0 \\
\hline Vancomycin & $2.25 \mathrm{~g} \times 14(\mathrm{q} 12 \mathrm{hr})$ & $\begin{array}{l}2.25 \mathrm{~g} \times 4(\mathrm{q} 12 \mathrm{hr}) \\
1.75 \mathrm{~g} \times 10(\mathrm{q} 12 \mathrm{hr})\end{array}$ & $1.75 \mathrm{~g} \times 14(\mathrm{q} 12 \mathrm{hr})$ & $1.75 \mathrm{~g} \times 14(\mathrm{q} 12 \mathrm{hr})$ & $1.75 \mathrm{~g} \times 5(\mathrm{q} 18 \mathrm{hr})$ \\
\hline \multirow[t]{5}{*}{ Surgery/events } & $\begin{array}{l}\text { (HD 1) Open Reduc- } \\
\text { tion and Internal Fix- } \\
\text { ation left Humerus }\end{array}$ & \multirow[t]{5}{*}{$\begin{array}{l}\text { (HD 8) Wound Exci- } \\
\text { sion \& Allograft }\end{array}$} & $\begin{array}{l}\text { (HD 15) Below Elbow } \\
\text { Amputation (utilizing } \\
\text { sedation \& CPNB) }\end{array}$ & \multirow{5}{*}{$\begin{array}{l}\text { (HD 23) Amputation } \\
\text { formalization } \\
\text { (HD 24) Supraclavicu- } \\
\text { lar CPNB Replaced } \\
\text { (HD 28) Dressing } \\
\text { Change Surgery, } \\
\text { Major }\end{array}$} & $\begin{array}{l}\text { (HD 30) Wound Exci- } \\
\text { sion \& Bilateral thigh } \\
\text { autograft }\end{array}$ \\
\hline & $\begin{array}{l}\text { (HD 2) Wound Exci- } \\
\text { sion \& Allograft }\end{array}$ & & (HD 17) Supraclavicu- & & (HD 30) Bilateral 'LIM' \\
\hline & (HD 2) Supraclavicular & & & & (HD 35) All CPNBs \\
\hline & CPNB performed & & & & removed \\
\hline & $\begin{array}{l}\text { (HD 4) Muscle flap } \\
\text { with allograft }\end{array}$ & & & & \\
\hline
\end{tabular}

IV: intravenous, HD: hospital day, CPNB: continuous peripheral nerve block. ${ }^{*}$ Intraoperative opioid administration. ${ }^{\dagger}$ Based on patient's 130 kg body weight. 
propofol sedation and replaced on HD 17. Amputation formalization occurred on HD 23, and APS carried out routine exchange of the supraclavicular CPNB catheter on HD 17 and HD 24 to reduce the potential risk for catheter site infection.

The patient then underwent a burn wound excision of the left arm and received an extensive split thickness skin graft $\left(1,140 \mathrm{~cm}^{2}\right)$ from both thighs on HD 30 . For donor site analgesia and to further mitigate opioid-induced delirium, APS performed an ultrasound-guided bilateral Lateral, Intermediate, and Medial femoral cutaneous nerves (LIM) CPNB intraoperatively using a total of $40 \mathrm{ml}$ of $0.375 \%$ bupivacaine. The novel LIM CPNB technique was performed by directing the needle caudally and medially above the fascia iliaca along the lateral border of the sartorius muscle. The sartorius muscle serves as an anatomical landmark as the lateral femoral cutaneous nerve enters the thigh lateral to the sartorius muscle near the LIM block insertion site. The intermediate and medial cutaneous branches of the femoral nerve respectively supply anterior and medial cutaneous thigh sensation and pierce the fascia iliaca just lateral to the sartorius muscle distally. Hydrodissection with local anesthetic allows the needle to advance easily in the correct plane just above the fascia iliaca. Ultrasound and anatomy images describe the nerve block procedure and relevant sonoanatomy (Figs 1-4) [5].

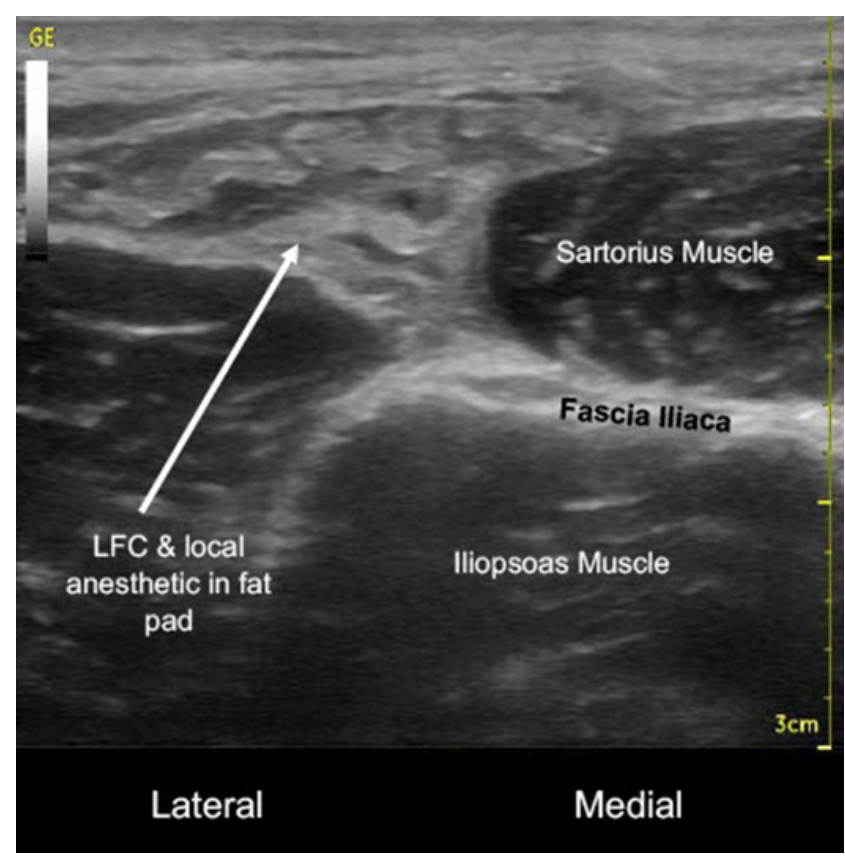

Fig. 1. Lateral femoral cutaneous (LFC) nerve \& local anesthetic in fat pad over fascia iliaca and iliopsoas muscle lateral to sartorius muscle with probe in transverse view (post-block).
For the next 5 days, APS continuously infused a total of 8 $\mathrm{ml} / \mathrm{hr}$ of $0.125 \%$ bupivacaine through a second electronic infusion pump utilizing a catheter tubing splitter (6 inch Bifurcated Blue Stripe Extension, ICU medical, USA) to the LIM blocks. On HD 35, APS held the supraclavicular and LIM block infusions to evaluate for remaining underlying pain. After confirming adequate analgesia without requirements for opioids, APS removed all three CPNB catheters without complication or evidence of infection.

\section{DISCUSSION}

The authors report this complex case demonstrating the successful use of a continuous unilateral supraclavicular nerve block for 5 weeks for ongoing left upper extremity pain supplemented with a novel LIM CPNB technique performed to control pain in the lateral, anterior, and medial cutaneous portions of both thighs. This comprehensive regional analgesic approach helped control postoperative pain, reduce opioid consumption, and facilitate therapy participation.

Throughout the 5-week supraclavicular CPNB infusion, the patient confirmed adequately controlled pain, utilizing only scheduled acetaminophen and requiring minimal opioids (Week 1 [prior to CPNB]: 159 oral morphine milligram equivalents [MME]; Week 2-5 average weekly oral MME:

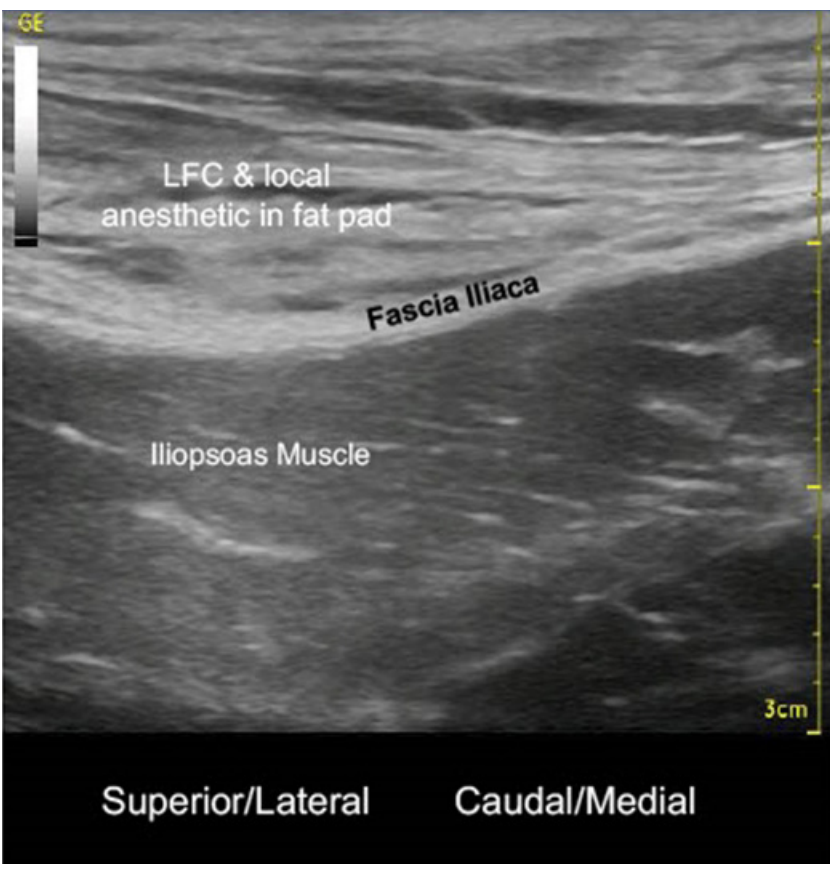

Fig. 2. Lateral femoral cutaneous (LFC) nerve \& local anesthetic in fat pad over fascia iliaca and iliopsoas muscle lateral to sartorius muscle with probe in near sagittal view (post-block). 


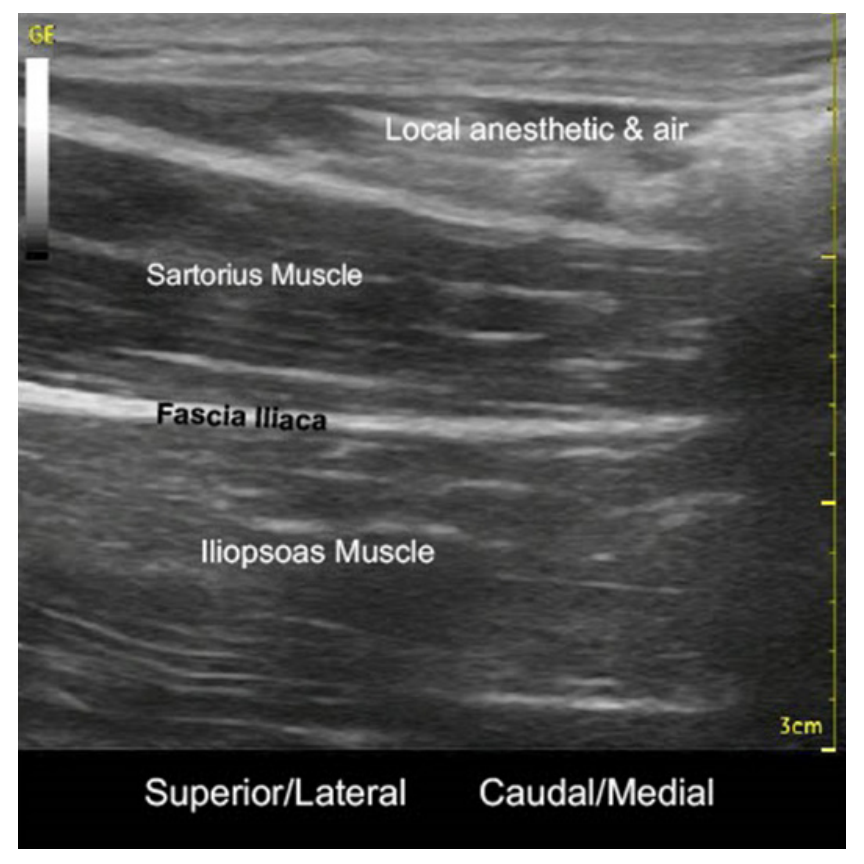

Fig. 3. Local anesthetic \& air seen tracking medially above sartorius muscle in near sagittal view (post-block).

8.88) for pain despite several painful surgeries, dressing changes, and participation with physical and occupational therapy. The patient exhibited no signs of local infection, local anesthetic systemic toxicity (LAST), and no evidence of residual weakness or numbness to the left arm. Throughout the 5-day continuous LIM block infusion, the patient denied thigh tenderness to palpation. Physical examination by APS demonstrated decreased temperature sensation to the lateral, anterior, and medial thigh and bilateral 5/5 strength of quadriceps each day. Consequently, the patient remained able to participate in physical and occupational therapy with LIM block infusions and without limitation due to quadriceps weakness or pain.

Adequate pain control facilitates earlier ambulation and discharge, improves functional recovery, and helps prevent other consequences of traumatic amputation, such as phantom and residual limb pain [6]. Utilization of long-term CPNB can reduce the risk of chronic post-surgical pain and mitigate downstream effects of prolonged exposure to opioids and related ORADEs, such as post-operative respiratory insufficiency, opioid dependence, and opioid-induced delirium experienced by this patient [7]. Patients suffering severe traumatic injuries are at risk for prolonged opioid exposure and, ultimately, opioid dependence [1]. This patient presented with a high risk for multiple ORADEs, given his past medical history and sustained trauma.

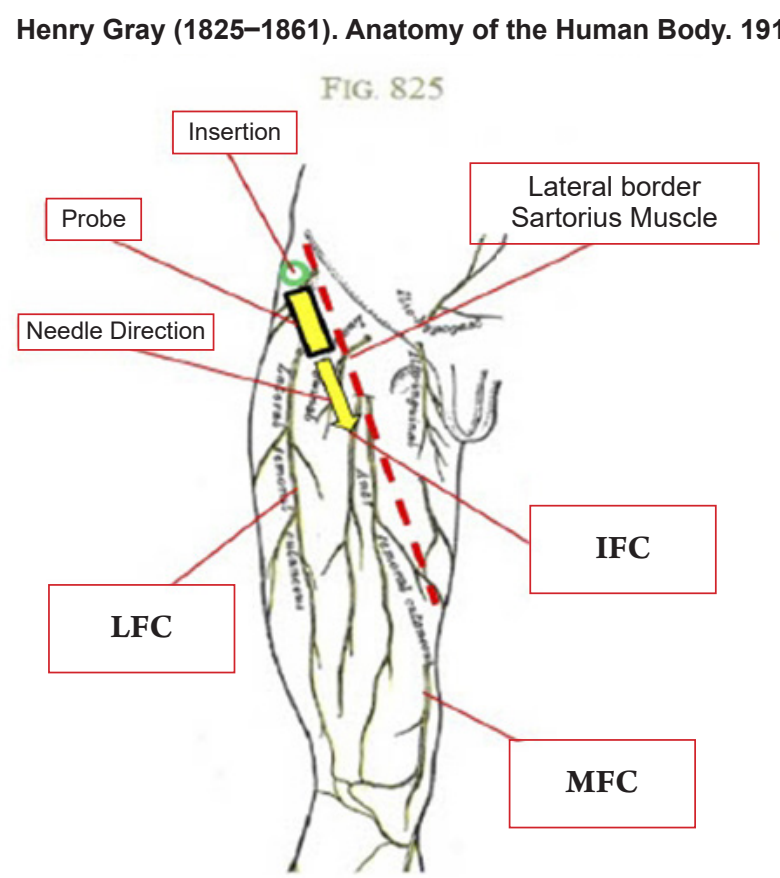

Fig. 4. Anatomy of a 'LIM' (Lateral [LFC], Intermediate [IFC], and Medial [MFC] Femoral cutaneous nerves) block with ultrasound probe orientation and needle direction. Adapted from the Lewis and Gray (Anatomy of the human body, 1918) [5].

Significant aspects of the LIM CPNB for thigh autograft pain include requiring a relatively low bupivacaine infusion rate to reduce the risk for developing LAST and preserving quadricep muscle strength to lower the risk of falls. Furthermore, the combined LIM CPNB consisting of the lateral, intermediate, and medial femoral cutaneous nerves performed in a single block provided reliable analgesia for the lateral, anterior, and medial cutaneous regions of both thighs. The anterior femoral cutaneous nerve, which carries the intermediate and medial femoral cutaneous nerves, additionally supplies cutaneous analgesia to the anteromedial knee [8]. In contrast to the novel technique described herein, other CPNB techniques traditionally utilized to control pain from thigh autograft harvesting, such as the femoral or fascia iliaca nerve blocks, produce quadriceps weakness and can lead to the common complication of patient falls [3]. The combined CPNBs provided an efficacious, alternative approach for analgesia, while promoting patient safety and participation in therapy.

Infection remains one of many concerns with CPNBs and has been associated with duration of catheter use [9]. Though the patient's requirement for antibiotics (Table 1) helped reduce the local infection due to prolonged catheter 
utilization risk, clinicians must keep the infection concern in mind during treatment. Many clinical practices have evolved by including the routine use of chlorhexidine skin preparation and cyanoacrylate glue for catheter site entry [4]. A specific recommendation regarding the duration of epidural or CPNB catheterization that is associated with an increased risk of infectious complications has not been issued, and studies have demonstrated minimal evidence of CPNB catheter-related infections despite prolonged use [10].

Concerns regarding nerve injury risk while replacing CPNBs with partially anesthetized nerves are valid, but ultrasound guidance and clinical experience mitigate this risk [11]. Given the extended infusion of CPNBs in this case, clinicians should consider the risk of LAST [12]. As standard practice, total daily local anesthetic usage is carefully calculated, and patients are continually monitored and verbally screened for LAST every 6 hours. As a final mitigation strategy, nurses maintain APS generated annual competencies for managing patients receiving CPNB.

While these risks are not trivial, the short and long-term risks associated with extended opioid exposure remain significant and should equally be considered $[1,7]$. Post-operative pain management with opioids independently serves as a risk factor for chronic opioid use even in opioid naïve patients $[1,2]$. This patient's injuries required multiple surgeries and would have required multiple weeks of escalating opioid doses.

Anesthesiologists involved in trauma and burn injuries could consider these techniques, particularly for patients with risk factors for addiction and ORADEs. Further investigation is needed to examine the risks and benefits of prolonged CPNBs and dressing management protocols in trauma patients. Evaluating optimal dosing for initial LIM block boluses and infusion rates, the risks and benefits of single injection and continuous LIM blocks versus fascia iliaca blocks or lateral femoral cutaneous blocks for thigh autografts are needed. Given the utilization of multiple CPNB, uncertainty arises regarding the efficacy and practicality of such approaches outside the trauma setting.

This case study demonstrates successful, prolonged usage of a supraclavicular CPNB in a patient with complex injuries. Further, the authors demonstrate a novel LIM CPNB requiring less anesthetic and providing extensive analgesia for bilateral thigh autografts while maintaining quadriceps strength. The analgesic plan in this case study eliminated previous episodes of opioid-induced delirium, facilitated participation in recovery, and removed concerns for respira- tory depression and chronic opioid use in a patient at particular risk for both issues.

\section{FUNDING}

None.

\section{ACKNOWLEDGEMENTS}

Figs. 1-3 courtesy of Jerry Jones, MD.

\section{CONFLICTS OF INTEREST}

No potential conflict of interest relevant to this article was reported.

\section{DATA AVAILABILITY STATEMENT}

Data sharing not applicable to this article as no datasets were generated or analyzed during the current study.

\section{AUTHOR CONTRIBUTIONS}

Conceptualization: Eric Ly, Jerry Jones. Formal analysis: Jerry Jones. Methodology: Ban Tsui. Investigation: Jerry Jones. Supervision: Ban Tsui, Jerry Jones. Validation: Jerry Jones. Writing - original draft: Eric Ly, Jerry Jones. Writing review \& editing: Eric Ly, Sai Velamuri, William Hickerson, David M. Hill, Jay Desai, Ban Tsui, Michael Herr, Jerry Jones.

\section{ORCID}

Eric Ly, https://orcid.org/0000-0001-5368-3712

Jay Desai, https://orcid.org/0000-0002-7072-2899

Michael Herr, https://orcid.org/0000-0002-8895-7733

Jerry Jones, https://orcid.org/0000-0001-7668-729X

\section{REFERENCES}

1. Oderda GM, Gan TJ, Johnson BH, Robinson SB. Effect of opioid-related adverse events on outcomes in selected surgical patients. J Pain Palliat Care Pharmacother 2013; 27: 62-70.

2. Rathmell JP, Wu CL, Sinatra RS, Ballantyne JC, Ginsberg B, Gordon DB, et al. Acute post-surgical pain management: a critical appraisal of current practice, December 2-4, 2005. Reg Anesth Pain Med 2006; 31(4 Suppl 1): 1-42.

3. Ilfeld BM, Duke KB, Donohue MC. The association between 
lower extremity continuous peripheral nerve blocks and patient falls after knee and hip arthroplasty. Anesth Analg 2010; 111: 1552-4.

4. Capdevila X, Bringuier S, Borgeat A. Infectious risk of continuous peripheral nerve blocks. Anesthesiology 2009; 110: 182-8.

5. Gray H, Lewis WH. Anatomy of the human body. New York, Lea \& Febiger. 1918.

6. Ketz AK. Pain management in the traumatic amputee. Crit Care Nurs Clin North Am 2008; 20: 51-7, vi.

7. Pisani MA, Murphy TE, Araujo KL, Slattum P, Van Ness PH, Inouye SK. Benzodiazepine and opioid use and the duration of intensive care unit delirium in an older population. Crit Care Med 2009; 37: 177-83.

8. Bjørn S, Nielsen TD, Moriggl B, Hoermann R, Bendtsen TF. Anesthesia of the anterior femoral cutaneous nerves for total knee arthroplasty incision: randomized volunteer trial. Reg Anesth Pain Med 2019 doi: 10.1136/rapm-2019-100904. [Epub ahead of print].

9. Compère V, Rey N, Baert O, Ouennich A, Fourdrinier V, Roussignol X, et al. Major complications after 400 continuous popliteal sciatic nerve blocks for post-operative analgesia. Acta Anaesthesiol Scand 2009; 53: 339-45.

10. Hebl JR. The importance and implications of aseptic techniques during regional anesthesia. Reg Anesth Pain Med 2006; 31: 311-23.

11. Neal JM, Brull R, Horn JL, Liu SS, McCartney CJ, Perlas A, et al. The second American Society of Regional Anesthesia and Pain Medicine evidence-based medicine assessment of ultrasound-guided regional anesthesia: executive summary. Reg Anesth Pain Med 2016; 41: 181-94.

12. Barrington MJ, Kluger R. Ultrasound guidance reduces the risk of local anesthetic systemic toxicity following peripheral nerve blockade. Reg Anesth Pain Med 2013; 38: 289-99. 